\title{
Treatment-seeking and out-of-pocket expenditure on childhood illness in a migrant tribal community in Bhubaneswar, Odisha State, India
}

\author{
Suchismita Mishra, Yadlapalli S. Kusuma \& Bontha V. Babu
}

To cite this article: Suchismita Mishra, Yadlapalli S. Kusuma \& Bontha V. Babu (2016):

Treatment-seeking and out-of-pocket expenditure on childhood illness in a migrant tribal community in Bhubaneswar, Odisha State, India, Paediatrics and International Child Health, DOI: 10.1080/20469047.2016.1245031

To link to this article: http://dx.doi.org/10.1080/20469047.2016.1245031

Published online: 06 Dec 2016.

Submit your article to this journal $\sqsubset$

Џ Article views: 7

View related articles $\sqsubset$

View Crossmark data ¿ 


\title{
Treatment-seeking and out-of-pocket expenditure on childhood illness in a migrant tribal community in Bhubaneswar, Odisha State, India
}

\author{
Suchismita Mishra루, Yadlapalli S. Kusuma ${ }^{1}$, Bontha V. Babu² ${ }^{2}$ \\ ${ }^{1}$ Department of Anthropology, Sambalpur University, Sambalpur, India, ${ }^{2} H e a l t h$ Systems Research Division, \\ Indian Council of Medical Research, New Delhi, India
}

Background: In India, migrant status, tribal affiliation and poverty render tribal migrants more vulnerable than any other group which leads to high treatment costs and the risk of low access to health care.

Objective: To examine treatment-seeking behaviour and out-of-pocket (OOP) expenditure on the treatment of childhood illnesses, with a focus on gender in a migrant tribal community in Bhubaneswar, eastern India.

Methods: A total of 175 households with a child aged 0-14 years and who had migrated within the last 12 years were selected from tribal-dominated slums. Data on health-seeking behaviour and expenditure on a recent illness in the youngest child were collected by interviewing mothers during October 2007 to March 2008.

Results: Of the 175 children, $78.8 \%$ had at least one episode of illness during the previous year. Of the total number of episodes, $71 \%$ had been treated and $61 \%$ of them had incurred OOP expenditure. A significantly lower proportion of episodes of illness in girls had been treated than in boys $(P=0.01)$ and incurred OOP expenditure $(P=0.05)$. Private health care was preferred and only $16.5 \%$ availed themselves of the government sources. About 89 and $87 \%$ of households of boys and girls, respectively, incurred OOP expenditure. A child's gender (female) ( $P=0.05)$, mother's education $(P=0.002)$ and type of illness $(P=0.002)$ were significantly associated with total OOP expenditure.

Conclusion: Further studies are warranted to address the low access to government health care and thereby reduce high OOP expenditure by tribal migrants on low incomes. Efforts are required to increase the ability of communities and health providers to identify and address the issues of gender and equity in health care along with a focus on culture-sensitive service provision.

Keywords: Migration, Health care-seeking behaviour, Treatment costs, Out-of-pocket expenditure, Gender

\section{Introduction}

Currently, $31.2 \%$ of India's population is urban, 50 cities have populations of over one million, and about $17 \%$ of urban households are in slums. ${ }^{1}$ The health indicators in slum populations are much poorer than urban averages and similar or even worse than those of rural populations. ${ }^{2}$ Children living in urban slums are exposed to the risk of infectious diseases, ${ }^{3}$ malnutrition ${ }^{4}$ and possibly impaired cognitive development. ${ }^{5}$ Overall child morbidity and mortality rates are many times higher in slums than in more privileged urban neighbourhoods. ${ }^{6}$

Internal migration is an important livelihood strategy in India. Tribal migrants are often in poorly remunerated jobs, principally in the informal sector, and suffer from various deprivations and handicaps, which also have to do with

Correspondence to: B V Babu, Health Systems Research Division, Indian Council of Medical Research, Ansari Nagar, New Delhi 110 029, India. Emails: babubontha@gmail.com, babubv@icmr.org.in

Current address: Centre for Study of Social Exclusion and Inclusive Policy, Bangalore University, Bengaluru, India the nature of urban policies and an absence of employer support. ${ }^{7}$ The changing pattern of urban tribal societies and their vulnerability owing to migration leads to inequities in health and access to health care. In several Indian cities, the infrastructure and manpower are insufficient to cater for the needs of the growing migrant population. ${ }^{8}$ In addition, the public health system has not taken account of the specific needs of the migrant population in designing services which are therefore not migrant-sensitive. ${ }^{9}$

Gender, one of the major social determinants of health, influences access to health care and gender disparities are greater amongst the poor. ${ }^{10}$ Some studies have demonstrated that the status of women in tribal societies is better in that girls are treated almost equally to boys and that this is apparent from birth. ${ }^{11}$ However, migration and contact with other cultures might affect attitudes to gender and child-care-seeking behaviour. ${ }^{12}$

Before migrating, tribes enjoy a cultural identity. Familiarity with an area and its facilities enables them to access well structured government health-care services. ${ }^{8}$ 
However, in general, the health of and access to health care of tribal populations is very poor. ${ }^{13}$ Migration to a new socio-cultural urban environment makes them more vulnerable and this leads to a failure to access public health-care services, and, thus, most of those who are underprivileged seek care from a variety of private health-care providers, ${ }^{14}$ which means high treatment costs. ${ }^{15}$ Hence, it is important to understand the treatment-seeking behaviour and pattern of household costs, referred to as out-of-pocket (OOP) expenditure. This paper aims to report treatment-seeking behaviour in migrant tribal families and to estimate OOP expenditure on treating childhood illnesses, with a focus on gender at the household level.

\section{Subjects and methods Study area}

The study was undertaken in the capital city of Odisha, Bhubaneswar, which has a population of $837737 .{ }^{1}$ There are 436 slums, 116 of which are authorised and 220 unauthorised. About $37 \%$ of the city's population live in these slums, and $67 \%$ of them are migrants. ${ }^{16}$ The city maintains 1 municipal hospital, 6 allopathic dispensaries and 11 homeopathic dispensaries. In addition, 1 state capital hospital and 17 primary health care centres are run by the state government, and there are several private clinics and hospitals.

\section{Study participants and research methods}

After a pilot study, tribal-dominated slums were identified and four were selected on the basis of the predominance of a tribal community. Most of these people are of the Santal tribe and have migrated from the hilly, forested areas of the Mayurbhanj district in Odisha State, and a few are from its neighbouring districts and have been in the city for the past 20 years. Households in the four slums were selected according to the following criteria: (i) the family had migrated within the last 12 years, and (ii) had a child aged 0-14 years. Altogether, 175 households met these criteria during the survey (October 2007 to March 2008). Data were collected through semi-structured interviews with the mothers by the first author. The mother tongue of this community is Santali, but a majority knew Odiya, the local state language. If the participant could not understand Odiya, another family member or neighbour who could speak both languages served as translator. Data on socio-economic status, demographic characteristics, details of recent illnesses in the youngest child during the past year including health care-seeking behaviour and health care expenditure were collected. The questionnaire was initially developed in English and translated into Odiya. It was pre-tested in a slum with some tribal households, but this was not included in this study.

\section{Statistical analysis}

Data were computerised and analysed using SPSS version 20.0. Various proportions and other descriptives relating to treatment-seeking behaviour and OOP expenditure were estimated. Univariate and multivariate analyses were undertaken to determine the influence of socio-economic and demographic variables on OOP. The dependent variable was total OOP expenditure and independent predictors were child gender, child age $(<1,2-5$ and $>5$ years $)$, monthly family income $(\leq \mathrm{INR}$ 2000, INR 2001-4000 and $>$ INR 4000), duration of family's stay in the city (1-3, 4-6, 7-9 and 10-12 years), mother's education, father's education (illiterate/no schooling, 1-5 years, 6-10 years and $>10$ years of schooling), mother's number of children and type of illness (wounds/skin diseases, measles, respiratory infections, fever, diarrhoeal diseases and other illnesses). Income and expenditure were recorded in Indian rupees (INR). Approximately INR 1 was equivalent to US\$ 0.025. Analysis of variance (ANOVA) was used for univariate analysis. The effect on OOP expenditure of all predictor variables was assessed by multiple regression through backward elimination.

\section{Results}

Of the 175 children, 138 (78.8\%) had at least one episode of illness in the last 12 months and treatment had been sought in 127 (72.6\%) cases (Table 1). In all, 209 episodes occurred in 175 children (1.2 illnesses per child). While $71 \%$ of episodes were treated, OOP expenditure was incurred for $61 \%$ (67.6\% in boys, $54 \%$ in girls). Gender differences were significant: treatment was sought $(P=0.01)$ and OOP expenditure $(P=0.05)$ was incurred for girls in a much lower proportion of illness episodes compared with boys.

In both genders, diarrhoea was prevalent (44.9\%), followed by malaria (23.2\%) and respiratory infections (17.4\%) (Table 2). Most children were treated in private health facilities (62.5\% boys, $56.4 \%$ girls), and $16.7 \%$ boys and $12.7 \%$ girls attended private homeopathic clinics (Table 3). Government health facilities were accessed for only $22.2 \%$ of boys and $9.1 \%$ girls. Herbal/traditional medicine, followed by pharmacy drugs was used more for girls than for boys (18.2\% girls vs. 13.9\% boys for herbal/ traditional medicine, and $14.5 \%$ girls vs. $8.3 \%$ boys for pharmacy drugs). In the majority of cases, these treatment sources were not far from their homes (Table 4). For a majority of children, treatment was sought from a source within one kilometre ( $48.6 \%$ of boys, $47.3 \%$ of girls).

The proportions of households which incurred OOP expenditure were 88.9 and $87.3 \%$ for boys and girls, respectively, and 11.1 and $12.7 \%$ of households did not spend any money on treatment for their son or daughter, respectively (Table 5). Total and individual components of OOP expenses were higher for boys than for girls. The mean OOP expenditure on boys was INR 280 (US\$ 7) (range INR 0-2200, US\$ 0-55), higher than that for girls (INR 171, US\$ 4.3) (range INR 0-1380, US\$ 0-34.5). Total OOP expenditure consisted of four components: travel, consultation, medicines and stay. The cost of 
Table 1 Sick children for whom treatment was sought

\begin{tabular}{|c|c|c|c|}
\hline & Boys $n=94(\%)$ & Girls $n=81(\%)$ & Total $n=175(\%)$ \\
\hline No. (\%) who were ill & $77(81.9)$ & $61(75.3)$ & $138(78.8)$ \\
\hline No. (\%) who sought treatment & $72(93.5)$ & $55(90.2)$ & $127(92.0)$ \\
\hline $\begin{array}{l}\text { No. (\%) of all sick children who were ill and for whom } \\
\text { treatment was sought with OOP expenditure }\end{array}$ & $64(83.1)$ & $48(78.7)$ & $112(81.2)$ \\
\hline No. of episodes of illness & 111 & 98 & 209 \\
\hline No. (\%) of episodes for which treatment was sought & $87(78.4)$ & $61(62.2)$ & $148(70.8)$ \\
\hline $\begin{array}{l}\text { No. (\%) of episodes for which treatment was sought } \\
\text { with OOP expenditure }\end{array}$ & $75(67.6)$ & $53(54.1)$ & $128(61.2)$ \\
\hline
\end{tabular}

Table 2 Distribution of most recent illnesses by gender

\begin{tabular}{|c|c|c|c|c|c|c|}
\hline \multirow[b]{2}{*}{ Illnesses } & \multicolumn{3}{|c|}{ Boys, $n=77$} & \multicolumn{3}{|c|}{ Girls, $n=61$} \\
\hline & $n$ & $\begin{array}{c}\text { Sought treat- } \\
\text { ment } n(\%)\end{array}$ & $\begin{array}{c}\text { Did not seek } \\
\text { treatment } n(\%)\end{array}$ & $n$ & $\begin{array}{l}\text { Sought treat- } \\
\text { ment } n(\%)\end{array}$ & $\begin{array}{l}\text { Did not seek } \\
\text { treatment } n(\%)\end{array}$ \\
\hline $\begin{array}{l}\text { Wounds and skin } \\
\text { diseases }\end{array}$ & 8 & $7(87.5)$ & $1(12.5)$ & 5 & $5(100)$ & 0 \\
\hline Measles & 1 & $1(100)$ & 0 & 3 & $3(100)$ & 0 \\
\hline $\begin{array}{l}\text { Respiratory infec- } \\
\text { tions }\end{array}$ & 15 & $13(86.7)$ & $2(13.3)$ & 9 & $9(100)$ & 0 \\
\hline Malaria & 16 & $16(100)$ & 0 & 16 & $14(87.5)$ & $2(12.5)$ \\
\hline Diarrhoeal diseases & 35 & 33 (94.3) & $2(5.7)$ & 27 & $23(85.2)$ & $4(14.8)$ \\
\hline Other illnesses & 2 & $2(100)$ & 0 & 6 & $1(100)$ & 0 \\
\hline Total illnesses & 77 & $72(93.5)$ & $5(6.5)$ & 61 & $55(90.2)$ & $6(9.8)$ \\
\hline
\end{tabular}

Table 3 Distribution of source of treatment for recent illness by gender

\begin{tabular}{lcc}
\hline & $\begin{array}{c}\text { Boys, } \\
n=72(\%)\end{array}$ & $\begin{array}{c}\text { Girls, } \\
n=55(\%)\end{array}$ \\
\hline $\begin{array}{l}\text { Source of treatment:* Private } \\
\text { clinics/hospitals }\end{array}$ & $45(62.5)$ & $31(56.4)$ \\
Government clinics/hospitals & $16(22.2)$ & $5(9.1)$ \\
Private homeopathic clinics & $12(16.7)$ & $7(12.7)$ \\
Herbal/traditional medicines & $10(13.9)$ & $10(18.2)$ \\
Clinics of non-government & $3(4.2)$ & $4(7.3)$ \\
organisations & $6(8.3)$ & $8(14.5)$ \\
Pharmacies & *Treatment was often sought from more than one source.
\end{tabular}

medicines includes the cost of investigations. Of these components, the cost of medicines accounted for most of the total OOP expenditure for both boys (78.6\%) and girls (72.5\%). Consultation charges contributed 13 and $18 \%$ of total OOP expenditure for boys and girls, respectively. The contribution of travel costs (4.9\% for boys, $5.7 \%$ for girls) and stay for treatment (3.5 and 3.8\% for boys and girls, respectively) were comparatively less.

Univariate analysis to examine variability in total OOP expenditure by some socio-economic and demographic variables demonstrated that mean total OOP expenditure was higher for boys but not significantly different from that for girls (Table 6). Similarly, there were no significant differences in mean total OOP expenditure by other variables. However, the type of illness had a significant influence on mean OOP expenditure $(P=0.001)$. There was greater OOP expenditure on measles and diarrhoea. Multivariate regression analysis demonstrated that child gender $(P=0.05)$, mother's education $(P=0.002)$ and type of illness $(P=0.002)$ were significantly associated with total OOP expenditure (Table 7). The gradient of OOP spending increased with the level of maternal education. The coefficients of determination showed that the predictor variables explained $13.7 \%$ of variation in total OOP expenditure by these households.

\section{Discussion}

This study reports data on OOP expenditure in the most vulnerable sector of the population, tribal migrants living in urban areas, which has not been investigated hitherto. Vulnerability owing to poverty, migrant status and tribal affiliation leads to the risk of poor health and low access to health care. The prevalence of diarrhoeal diseases, malaria and respiratory infections were high. Worldwide, these are the most common acute childhood illnesses and are major contributors to child mortality. ${ }^{17,18}$ A significantly lower proportion of illnesses were treated in girls $(P=0.01)$ than in boys and expenditure was incurred for girls significantly less frequently $(P=0.05)$ than for boys. There was a high dependence on private health care. In their original areas, tribal communities usually rely heavily on government-run primary health centres and institutions, along with their traditional health care systems. ${ }^{19}$ The tribes enjoy a cultural identity, and familiarity with the area and its various facilities enables them to access well organised government health care services. ${ }^{8}$ However, moving to a new urban environment makes them vulnerable and they can miss out on public health care services. The socio-economic inequities in an urban environment may affect access to and use of health services ${ }^{20,21}$ and the selection of an appropriate health care provider. ${ }^{22,23}$ Also, private facilities within two kilometres might be one of the reasons why they are used instead of the government facilities which are further away. While convenience (of distance and time), prompt 
Table 4 Distance travelled for treatment by gender

\begin{tabular}{lcc}
\hline & Boys, $\boldsymbol{n}=\mathbf{7 2}(\%)$ & Girls, $\boldsymbol{n}=\mathbf{5 5}(\%)$ \\
\hline$<1 \mathrm{kms}$ & $35(48.6)$ & $26(47.3)$ \\
$1-2 \mathrm{kms}$ & $23(31.9)$ & $22(40.0)$ \\
$3-5 \mathrm{kms}$ & $8(11.1)$ & $4(7.3)$ \\
$>5 \mathrm{kms}$ & $6(8.3)$ & $3(5.4)$ \\
Median (range), kms & $2(0-200)$ & $2(0-99)$ \\
\hline
\end{tabular}

Note: kms, kilometres; analysis of variance for mean distance, $F=0.262, P=0.61$

Table 5 Various components of out of pocket (OOP) expenditure for the treatment sought by the gender of the child

\begin{tabular}{|c|c|c|c|}
\hline Expenditure & Boys, $n=72$ & Girls, $n=55$ & $P$-values \\
\hline \multicolumn{4}{|c|}{ Expenditure on travel: } \\
\hline Mean (SD), INR & $13.7(40.6)$ & $9.8(27.7)$ & 0.27 \\
\hline \multicolumn{4}{|c|}{ Expenditure on consultation: } \\
\hline Mean (SD), INR & $36.3(56.4)$ & $30.8(40.2)$ & 0.27 \\
\hline \multicolumn{4}{|c|}{ Expenditure on medicines: } \\
\hline Mean (SD), INR & $220.2(345.6)$ & $123.8(211.9)$ & 0.03 \\
\hline \multicolumn{4}{|c|}{ Expenditure on stay: } \\
\hline Mean (SD), INR & 9.7 (63.2) & $6.5(23.8)$ & 0.36 \\
\hline \multicolumn{4}{|l|}{ Total OOP } \\
\hline \multicolumn{4}{|l|}{ expenditure: } \\
\hline Mean (SD), INR & $280.0(432.2)$ & $170.8(259.7)$ & 0.05 \\
\hline
\end{tabular}

care and a courteous service are cited as reasons for using private health care providers, the cost of treatment, ease of access and the perceived severity of illness are the reasons for seeking treatment from traditional healers. ${ }^{18,24}$ Pharmacists were approached as they are close to home, consultation is free and only the cost of drugs is incurred. ${ }^{24}$

A considerable amount was spent (INR 233, approximately US\$ 5.8) on each episode of illness. This is lower than national estimates, but little interpretative weight can be attached to this difference because of the restricted nature of the sample. These expenditures are quite considerable for tribal migrant households whose average monthly income was only INR 2594 (US\$ 65). The Indian national sample survey (NSSO)'s data estimated that, overall, 4.7\% of total household OOP expenditure is on health care. ${ }^{25}$ The study population spent an even greater proportion of household income on health care. The NSSO's nationwide consumer expenditure survey found that, compared with the general population, scheduled tribes spent even more on health care. ${ }^{26}$ Orissa's Public Health Beneficiary Survey in 2010 demonstrated that the gap between wealthy and poor households with regard to OOP expenditure on outpatient treatment at public facilities was only $16 \%$, with the

Table 6 Results of univariate analysis of total OOP expenditure vs. other characteristics

\begin{tabular}{|c|c|c|c|c|}
\hline Variable & No. of children & $\begin{array}{l}\text { Mean (SD) total OOP } \\
\text { expenditure, INR }\end{array}$ & ANOVA ( $F$-value) & $P$-values \\
\hline \multicolumn{5}{|l|}{ Child's gender } \\
\hline Boy & 72 & $280.0(432.2)$ & 2.75 & 0.10 \\
\hline Girl & 55 & $170.8(259.7)$ & & \\
\hline \multicolumn{5}{|l|}{ Child's age, yrs } \\
\hline $0-1$ & 35 & $214.3(380.9)$ & 0.45 & 0.64 \\
\hline $2-5$ & 63 & $262.9(349.5)$ & & \\
\hline$>5$ & 29 & $189.4(407.4)$ & & \\
\hline \multicolumn{5}{|l|}{ Monthly family income } \\
\hline INR 0-2000 & 50 & $231.6(360.4)$ & 0.01 & 0.99 \\
\hline INR 2001-4000 & 73 & 231.8 (380.9) & & \\
\hline$>$ INR 4000 & 4 & 262.5 (393.0) & & \\
\hline \multicolumn{5}{|c|}{ Duration of stay in the city, yrs } \\
\hline $1-3$ & 22 & $256.2(256.3)$ & 2.03 & 0.11 \\
\hline $4-6$ & 35 & $254.4(436.6)$ & & \\
\hline $7-9$ & 26 & $78.5(115.7)$ & & \\
\hline $10-12$ & 44 & $294.8(438.4)$ & & \\
\hline \multicolumn{5}{|l|}{ Mother's education, yrs } \\
\hline Illiterate & 89 & $190.3(294.3)$ & 2.37 & 0.07 \\
\hline $1-5$ & 15 & $244.1(365.7)$ & & \\
\hline $6-10$ & 18 & $338.1(450.1)$ & & \\
\hline 11 & 5 & 574.0 (921.0) & & \\
\hline \multicolumn{5}{|l|}{ Father's education, yrs } \\
\hline Illiterate & 53 & $241.8(368.5)$ & 0.17 & 0.91 \\
\hline $1-5$ & 18 & $217.8(315.4)$ & & \\
\hline $6-10$ & 45 & 245.7 (435.0) & & \\
\hline 11 & 11 & $160.4(112.3)$ & & \\
\hline \multicolumn{5}{|l|}{ No. of children } \\
\hline One & 38 & $280.4(390.6)$ & 1.11 & 0.35 \\
\hline Two & 34 & $241.2(360.2)$ & & \\
\hline Three & 29 & 262.7 (477.3) & & \\
\hline More than three & 26 & $118.5(143.8)$ & & \\
\hline \multicolumn{5}{|l|}{ Type of illness } \\
\hline Wounds/skin diseases & 11 & $80.0(95.6)$ & 4.22 & 0.001 \\
\hline Measles & 4 & 319.5 (153.0) & & \\
\hline Respiratory infections & 22 & $102.7(95.0)$ & & \\
\hline Malaria & 30 & $146.2(214.9)$ & & \\
\hline Diarrhoeal diseases & 56 & $312.9(425.7)$ & & \\
\hline Other & 4 & 807.5 (1009.7) & & \\
\hline Total & 127 & 232.7 (370.3) & - & - \\
\hline
\end{tabular}

OOP, out-of-pocket; INR, Indian rupees ( $\approx$ US\$ 0.025); ANOVA, analysis of variance. 
Table 7 Results of multiple regression analysis of OOP expenditure vs. other characteristics

\begin{tabular}{lcccc}
\hline Independent variables & Coefficient & $\begin{array}{c}\text { Standard error of } \\
\text { coefficient }\end{array}$ & $\boldsymbol{P}$-values & $\begin{array}{c}\text { Coefficient of } \\
\text { determination }\end{array}$ \\
\hline Constant & 84.2 & 142.0 & 0.55 & $R^{2}=0.16$ \\
Child's gender & -112.6 & 61.9 & 0.05 & Adjusted $R^{2}=0.14$ \\
Child's age & 5.0 & 46.1 & 0.91 & 0.78 \\
Family income & 15.9 & 58.1 & 0.65 & \\
Duration of living in the city & 12.8 & 28.1 & 0.002 & 0.09 \\
Mother's education & 123.7 & 39.0 & 0.68 & \\
Father's education & -55.3 & 32.7 & $\mathbf{0 . 0 0 2}$ & \\
Mother's number of & -12.9 & 31.1 & & \\
children & & 23.9 & & \\
Type of illness & 76.6 & &
\end{tabular}

average OOP expenditure being INR 149 (US\$ 3.7) and INR 178 (US\$ 4.4), respectively, in the lowest and highest income groups. ${ }^{27}$ Tribal households are among the lowest income groups. This survey reported that the greatest share of OOP expenditure was on medicines..$^{27}$ Based on other national estimates also, the greatest expenditure was on medicines in both public and private health care facilities (38-66\% of total treatment costs) ${ }^{28}$ Regardless of whether public or private health care is accessed, high spending on medicines constitutes the bulk of OOP expenditure. This is because drugs are not available in public health care institutions. ${ }^{27}$ The second largest component was consultation fees: on average, 22 and $40 \%$ of OOP expenditure was, respectively, in public and private health care facilities. ${ }^{28}$

Data on treatment-seeking and OOP expenditure demonstrates gender bias in families. Households spent more money on treatment for boys than for girls, and this overt discrimination is found in all parts of India. ${ }^{29}$, 30 This discrimination manifests in the reporting of illnesses,${ }^{31}$ making the decision to seek health care ${ }^{32}$ and preferring private sector health services to public ones. ${ }^{33}$ Discrimination in this migrant community can be attributed to the influence of neighbouring non-tribal households. Migration to a new culture means a new lifestyle and new norms with regard to gender, roles and statutes. Apart from gender, many other factors may influence the decision to seek treatment for a sick child. In this community, mother's education $(P=0.002)$ and the type of illness in the child $(P=0.002)$ significantly determined OOP expenditure. The literature suggests that a mother's level of education is associated with treatment-seeking behaviour for a sick child; ${ }^{34}$ however, there was no evidence of its effect on health-care expenditure. The type of illness has an impact on treatment-seeking behaviour and health care expenditure. ${ }^{34}$ The expenditure on minor illnesses was low because they were simply treated with medicines bought from pharmacists or by herbal/home remedies. Treatment for diarrhoea and measles incurred greater expenditure and diarrhoea was often treated by private practitioners. Children are likely to be taken for treatment to various sources, depending on the perceived seriousness of the illness by the caretakers. ${ }^{24,31}$

Recent Indian studies report that health care access increased significantly after introduction of the
Government of India's National Health Mission and Government-sponsored insurance initiatives. ${ }^{35-37}$ OOP expenditure also decreased after these schemes were introduced. ${ }^{38}$ However, no one in this study had subscribed to these schemes, and research indicates that their impact is less apparent in vulnerable communities such as tribal ones. ${ }^{38}$ Also, in the absence of effective health care targeting, benefits from public services will disproportionately flow to the wealthier in India. ${ }^{39,40}$

Even the smallest expenditure on health care can be financially disastrous for the poor; almost all their available resources are for basic needs such as food and shelter, and they are less able to afford even very low health care expenditure. Hence, free public health care must be available to these urban poor, and local government should include them in government-sponsored insurance schemes to protect them from catastrophes caused by the cost of health care. Physical inaccessibility to health facilities is a major obstacle. ${ }^{9}$ Cities provide many health facilities at a range of costs, and in Indian cities there is a burgeoning, largely unregulated private sector and a beleaguered public sector. Quality of care and choice of an appropriate provider is therefore problematic. ${ }^{41}$ Hence, this study advocates the development of a policy to improve access to health care for the considerable migrant tribal population in almost all Indian cities.

The following are some strengths and limitations of the study. It was not possible to select the sample from all migrant tribal communities in the city on the basis of probability; instead, it was limited to four slums predominantly inhabited by tribal communities. The external validity is therefore a limit to generalising these findings, but all three contexts for generalisation, i.e. people, situation and time are similar to other tribal migrant communities. The information collected was based on retrospective reporting of the participants' experience, which includes reporting bias on the narration of illness which could result in underestimation of illness prevalence. As the study's focus was on health care seeking and expenditure, this underestimation does not per se threaten the validity of the findings. Also, the data on OOP expenditure report only OOP expenditure and not indirect losses related to illnesses, which is of concern with regard to assessing the overall burden of illness. Illness can lead to other losses such as a mother's or caregiver's wages when 
a child is ill, and assets might have to be sold or mortgaged. These indirect costs were not examined in the OOP expense data. The contribution of these losses was minor in the study population and the main conclusions are not affected.

To conclude, the study addresses the treatment-seeking behaviour, poor access to government health care and high OOP expenditure in relation to low income in migrant tribal communities in a city who attempt to adapt to an urban culture by holding traditional perceptions alongside modern facilities. Hence, a comprehensive migrant-sensitive health care system embracing the above cultural issues is required. As poverty and migration exacerbate gender discrimination, this discrimination needs to be addressed in the state's efforts to alleviate poverty and improve the health and education of both genders.

\section{Disclaimer statements}

\section{Conflicts of interest}

None

\section{Funding}

None

\section{Ethics approval}

The study protocol was approved by the Doctoral Committee of Sambalpur University which reviewed the ethics and approved the research programme.

\section{ORCID}

Yadlapalli S. Kusuma (D) http://orcid.org/0000-0002-43556274

Bontha V. Babu (D) http://orcid.org/0000-0001-5096-2222

\section{References}

1 Government of India. Census of India - Provisional Population Tables. New Delhi: Registrar General and Census Commissioner of India, Government of India, 2011.

2 Montgomery MR, Hewett PC. Urban poverty and health in developing countries: household and neighborhood effects. Demography. 2005;42:397-425

3 Hughart N, Silimperi RD, Khatun J, Stanton B. A new strategy to reach high risk urban children in Bangladesh, Urban Volunteers. Trop Geogr Med. 1992;44:142-8.

4 Choudhary R, Sharma A, Agarwal KS, Kumar A, Sreenivas V, Puliyel JM. Building for the future: influence of housing on intelligence quotients of children in an urban slum. Health Policy Plan. 2002;17:420-4.

5 Pryer JA, Rogers S, Normand C, Rahman A. Livelihoods, nutrition and health in Dhaka slums. Public Health Nutr. 2002;5:613-8.

6 More N, Bapat U, Das S, Barnett S, Costello A, Fernandez A, et al. Inequalities in maternity care and newborn outcomes: one-year surveillance of births in vulnerable slum communities in Mumbai. Int J Equity Health. 2009;8:21.

7 UNICEF. Internal Migration in India: An Overview of its Features, Trends and Policy Challenges. New Delhi: Social and Human Sciences Sector, 2011

8 Babu BV, Swain BK, Mishra S, Kar SK. Primary healthcare services among a migrant indigenous population living in an eastern Indian city. J Immigr Minor Health. 2010;12:53-9.

9 Mishra S, Kusuma YS, Babu BV. Migration and health-care access: barriers to access government health services by migrant tribal community living in an eastern Indian city. Int J Med Sci Public Health. 2015;4:101-8.
10 Kaur M, Sodhi SK, Kaur P, Singh J, Kumar R. Gender differences in health care seeking behaviour of tuberculosis patients in Chandigarh. Indian J Tuberc. 2013;60:217-22.

11 Deogaonkar S, Deogaonkar SG. The tribal girl child. In: Devasia L, Devasia VV, eds. Girl Child in India. New Delhi: Ashish Publishing House, 1991. pp. 101-6.

12 Mishra S, Kusuma YS, Babu BV. Concepts of health and illness: continuity and change among migrant tribal community in an Eastern Indian city. Anthropol Noteb. 2013;XIX:61-9.

13 Mohindra KR, Labonté R. A systematic review of population health interventions and Scheduled Tribes in India. BMC Public Health. 2010;10:4824.

14 Gupta I, Guin P. Health status and access to health services in Indian slums. Health. 2015;7:245-55.

15 Awasthi S, Pande VK. Family expenditure on sickness episodes of pre-school children in urban slums of Lucknow, North India. J Trop Pediatr. 1998;27:1-5.

16 PRIA. Government Led Exclusion of Urban Poor Greater Contribution and Lesser Recipient-Bhubaneswar Study Report. New Delhi: Participatory Research in Asia, 2014. Available from: https://terraurban.files.wordpress.com/2014/01/bhubaneswar_study_ report 12 march.pdf

17 Liu L, Johnson HL, Cousens S, Perin J, Scott S, Lawn JE, et al. Global, regional, and national causes of child mortality: an updated systematic analysis for 2010 with time trends since 2000. Lancet. 2012;379:2151-61

18 Geldsetzer P, Williams TC, Kirolos A, Mitchell S, Ratcliffe LA, KohliLynch MK, et al. The recognition of and care seeking behaviour for childhood illness in developing countries: a systematic review. PLoS ONE. 2014;9:e93427.

19 Verma MK, Shah A. Health, tradition and awareness: a perspective on the tribal health care practices. Soc Res. 2014;2:82-91.

20 Makinen M, Waters H, Rauch M, Almagambetova N, Bitrán R, Gilson L, et al. Inequalities in health care use and expenditures: empirical data from eight developing countries and countries in transition. Bull WHO. 2000;78:55-65.

21 Kusuma YS, Kumari R, Pandav CS, Gupta SK. Migration and immunization: determinants of childhood immunization uptake among socioeconomically disadvantaged migrants in Delhi, India. Trop Med Int Health. 2010;15:1326-32.

22 Srivastava NM, Awasthi S, Agarwal GG. Care-seeking behavior and out-of-pocket expenditure for sick newborns among urban poor in Lucknow, northern India: a prospective follow-up study. BMC Health Serv Res. 2009;9:1.

23 Thriveni BS, Bhojani U, Mishra A, Amruthavalli, Devadasan R, Munegowda CM. Health system challenges in delivering maternal health care: evidence from a poor urban neighbourhood in South India. BMC Proc. 2012;6(Suppl 5):13.

24 Mishra S, Kusuma YS, Babu BV. Pluralistic care and therapeutic itineraries among a migrant tribal community in an Eastern Indian city. J Anthropol Soc Oxf. 2014;6:61-78.

25 Gupta I. Out-of-pocket expenditures and poverty: estimates from NSS 61st round. Paper presented for consideration of the Expert Group on Poverty, Planning Commission. Delhi: Institute of Economic Growth, 2009. Available from: http://planningcommission.gov.in/ reports/genrep/indrani.pdf

26 Karan A, Selvaraj S, Mahal A. Moving to universal coverage? Trends in the burden of out-of-pocket payments for health care across social groups in India, 1999-2000 to 2011-12. PLoS ONE. 2014;9:e105162.

27 Orissa Technical and Management Support Team. Out of pocket spending on health in Odisha - current status and some recommendations. Bhubaneswar: Department of Health and Family Welfare, Government of Orissa, 2010.

28 Government of India. National Health Accounts India - 2004-05 (With provisional estimates from 2005-06 to 2008-09). New Delhi: Ministry of Health and Family Welfare, Government of India, 2009. Available from: http://planningcommission.nic.in/reports/genrep/ health/National Health Account 04 05.pdf

29 Pandey A, Sengupta PG, Mondal SK, Gupta DN, Manna B, Ghosh S, et al. Gender differences in healthcare-seeking during common illnesses in a rural community of West Bengal, India. J Health Popul Nutr. 2002;1:306-11.

30 Varma GR, Bhavani PSV, Mishra S, Babu BV. Gender bias in utilization of healthcare among rural and tribal children of Visakhapatnam district, Andhra Pradesh. South Asian Anthropol. 2009;9:165-8.

31 Yoder PS, Hornik RC. Perceptions of severity of diarrhoea and treatment choice: a comparative study of HealthCom sites. J Trop Med Hyg. 1994;97:1-12.

32 Pokhrel R, Snow H, Dong B, Hidayat S, Flessa R, Sauerborn R. Gender role and child health care utilization in Nepal. Health Policy. 2003;74:100-9. 
33 Selvaraj SKA. Deepening health insecurity in India: evidence from national sample surveys since 1980s. Econ Polit Wkly. 2012;XLIV:55-60.

34 Chandrashekhar T, Sreeramareddy CT, Sathyanarayana TN, Kumar HNH. Utilization of health care services for childhood morbidity and associated factors in India: a national cross-sectional household survey. PLoS One. 2012; 7:e51904.

35 Devadasan N, Criel B, Van Damme W, Manoharan S, Sarma PS, Van der Stuyft P. Community health insurance in Gudalur, India, increases access to hospital care. Health Policy Plan. 2010;25:145-54.

36 Mazumdar S, Mills A, Powell-Jackson T. Financial incentives in health: new evidence from India's Janani Suraksha Yojana. SSRN Working Paper, 2011. Available from: http://ssrn.com/abstract=1935442

37 Sood N, Bendavid E, Mukherji A, Wagner Z, Nagpal S, Mullen P. Government health insurance for people below poverty line in India: quasi-experimental evaluation of insurance and health outcomes. BMJ. 2014;349:g5114

38 Fan VY, Karan A, Mahal A. State health insurance and out-of-pocket health expenditures in Andhra Pradesh, India. Int $\mathrm{J}$ Health Care Finance Econ. 2012;12:189-215.

39 Mahal A, Singh J, Afridi F, Lamba V, Gumber A, Selvaraju V. Who Benefits from Public Health Spending in India? New Delhi: National Council for Applied Economic Research, 2000.

40 O'Donnell O, van Doorslaer E, Rannan-Eliya RP, Somanathan A, Adhikari SR, Harbianto D, et al. The incidence of public spending on healthcare: comparative evidence from Asia. World Bank Econ Rev. 2007;21:93-123.

41 Skordis-Worrall J, Pace N, Bapat U, Das S, More NS, Joshi W, et al. Maternal and neonatal health expenditure in mumbai slums (India): a cross sectional study. BMC Public Health. 2011;11:150. 